\title{
A role for DRAK2 in the germinal center reaction and the antibody response
}

\author{
AHMED AL-QAHTANI ${ }^{1,2}$, ZHENMING XU ${ }^{1,2}$, HONG ZAN $^{1,2}$, CRAIG M. WALSH $^{1,2}$, and \\ PAOLO CASALI ${ }^{1,2,3}$ \\ ${ }^{1}$ Center for Immunology, University of California, Irvine, CA 92697-4120 \\ 2 Department of Molecular Biology \& Biochemistry, School of Biological Sciences, University of \\ California, Irvine, CA 92697-4120 \\ ${ }^{3}$ Department of Medicine, School of Medicine, University of California, Irvine, CA 92697-4120
}

\begin{abstract}
DAP-related apoptotic kinase-2 (DRAK2), a DAP kinase family member, is highly expressed in B and $T$ lymphocytes in the human and the mouse. To determine whether DRAK2 plays a role in B cell activation and differentiation, we analyzed germinal centers (GCs) and the specific antibody response to NP in $d \mathrm{rak}^{-/-}$mice immunized with the thymus-dependent (TD) conjugated hapten $\mathrm{NP}_{16}$-CGG. In drak $^{-1-}$ mice, spleen GCs were normal in size and morphology, but their number was reduced by as much as five-fold, as compared to their wild-type littermates. This was not due to a defect in B cell proliferation, as the BrdU uptake was comparable in DRAK2-deficient and wild-type B cells. Rather, the proportion of apoptotic GC B and T cells in $d r a k 2^{-/-}$mice was significantly higher than that in wild-type control mice, as shown by 7-AAD and TUNEL staining. In rrak $^{-/-}$mice, the generation of high affinity IgG antibodies was impaired in spite of the seemingly normal somatic hypermutation (SHM) and class switch DNA recombination (CSR)

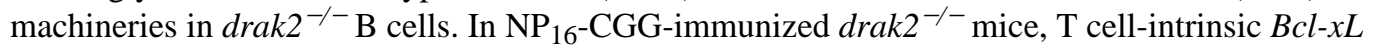
transgene expression increased the number of GCs and rescued the high affinity IgG response to NP. These findings suggest a novel role for DRAK2 in regulating the GC reaction and the response to TD antigens, perhaps through increased survival of T cells and enhanced B cell positive selection. They also suggest that DRAK2-deficiency is not involved in regulating intrinsic B cell apoptosis.
\end{abstract}

\section{Keywords}

B cells; antibodies; spleen and germinal centers; molecular biology; transgenic/knockout mice

\section{Introduction}

DRAK2 belongs to the DAP (death-associated protein) kinase family of pro-apoptotic serine/threonine kinases [1]. All five members of this family (DAP kinase, DAPK2, ZIP kinase, DRAK1 and DRAK2) share a homology of the sequence restricted to their Nterminal kinase domain [2]. The $\mathrm{C}$-terminal regions, however, are diverse and implicated in specific signal transduction pathways. DAP kinases are involved in both extrinsic and intrinsic apoptotic pathways [3] and DRAK2 was shown to induce apoptosis upon overexpression in several human tumor-derived cell lines [4]. DAP kinases are localized in

Correspondence: Dr. Paolo Casali, Center for Immunology, 3028 Hewitt Hall, University of California, Irvine, California 92697-4120. pcasali@uci.edu. 
both the cytoplasm and the nucleus [3]; in COS-7 (human), Caco-2 (human), NIH 3T3 (mouse) and NRK (rat) cells, DRAK2 is primarily localized in the nucleus [5-7], and in ACL-15 (rat) cells, primarily in the cytoplasm [7]. In non-stimulated Jurkat T cells, a stably expressed DRAK2-GFP fusion protein was shown to be localized in the nucleus [5]. However, upon stimulation with phorbol myristate acetate (PMA) and phytohemagglutin (PHA), two signals mimicking the antigenic stimulation of $\mathrm{T}$ cell receptors (TCRs), DRAK2-GFP was exported from the nucleus to the cytoplasm [5], suggesting a potential regulatory mechanism for DRAK2 activities in T cells. Further, a C-terminal truncated DRAK2 mutant, which possesses an intact $\mathrm{N}$-terminal kinase domain, is localized to the cytoplasm but fails to induce apoptosis in NIH $3 \mathrm{~T} 3$ cells, suggesting that the $\mathrm{C}$ terminus of DRAK2 is required for its nuclear localization and induction of apoptosis [5, 7]. Finally, in T cell line Jurkat, primary thymocytes as well as resting B cells, DRAK2 is autophosphorylated at Ser12 upon antigen receptor stimulation and its kinase activity is regulated by intracellular calcium mobilization [8].

DRAK2 shares 52\% homology with the DAP kinase, which was found to associate with TNF $\alpha$ receptor and Fas-associated protein with death domain (FADD) to inhibit apoptosis [9]. DRAK2 has been suggested to plays a role in UV-induced apoptosis [7] and its overexpression in NIH 3T3 cells or in transgenic T cells induces apoptosis [1, 10]. However, ectopic expression of DRAK2 in NIH 3T3 cells or primary T cells using retroviral transduction did not promote apoptosis [5]. Further, DRAK2-deficient T cells showed no apparent defects in the apoptosis regulation upon stimulation in vitro with peptide-pulsed antigen presenting cells (APCs), an agonistic anti-CD3 monoclonal antibody (mAb), antiFas $\mathrm{mAb}$, dexamethasone, staurosporine, etoposide or $\gamma$-irradiation [11]. In addition, drak $2^{-/-}$mice showed resistance to myelin oligodendrocyte glycoprotein (MOG)-induced experimental autoimmune encephalomyelitis (EAE) [11]. However, DRAK2 was found to be dispensable for the $\mathrm{T}$ cell recruitment into the central nervous system (CNS) following infection of mice with mouse hepatitis virus (MHV), suggesting that the EAE resistance in drak2 $2^{-1-}$ mice was not due to an altered T cell trafficking in CNS [12]. Furthermore, drak2 ${ }^{-/}$memory T cells specific for MHV resulted in an accelerated clearance of MHV from the brain when transferred into MHV-infected $\mathrm{Ragl}^{-/}$mice, suggesting an important role for DRAK2 in regulating protective immunity against viral pathogens [13].

A potential role of DRAK2 in modulating T cell activation and survival is relevant to the dynamics of the GC reaction and the events that orchestrate the generation of the antibody response $[14,15]$. GC formation is distinctive of $\mathrm{T}$ cell-dependent immune responses [16, 17] and the GC reaction is critical for the generation of mature immune responses involving high affinity, class-switched antibodies, and plasma cells and memory B cells [18]. The generation of B cells expressing high affinity and class-switched antibodies is achieved through three sequential steps in the GC. It starts with the activation of B cells by primed $\mathrm{T}$ helper $\left(T_{h}\right)$ cells, resulting in rapid B cell proliferation and clonal expansion, which generate a diverse B cell receptor (BCR) repertoire for antigen through active SHM and CSR [19]. Next, B cells bearing mutated BCRs with high affinity for antigen are positively selected by follicular dentritic cells (FDC) through an antigen-dependent mechanism [20-25]. Finally, the positively selected $B$ cells are provided a survival signals by $T_{h}$ cells to differentiate into plasma and memory B cells, which have the capacity to produce high affinity class-switched antibodies $[26,27]$.

Despite accumulating evidence that DRAK2 is involved in T cell signaling and autoimmunity $[5,8,10]$, little is known about its role in the development of a specific antibody response. Here, we used DRAK2-deficient B cells and DRAK2-deficient mice to address the role of DRAK2 in the maturation of the antibody response. Our findings suggest 
important roles for DRAK2 in the development of GCs and the generation of high affinity and class-switched antibodies to TD antigens.

\section{Materials and Methods}

\section{Mice and Immunization}

Generation of $\mathrm{Drak} 2^{-{ }^{-}}$mice were previously described [11]. The Bcl- $x L$ transgene was generated by the insertion of the human Bcl-xL cDNA downstream of the lck proximal promoter [28]. Mice used in the experiments were backcrossed to C57Bl/6 for at least six generations and were between 8 and 12 weeks of age and without apparent pathological symptoms. For immunization, mice were intraperitoneally injected with a TD antigen, 4hydroxy-3-nitrophenylacetyl-chicken gamma globulin $\left(\mathrm{NP}_{16}\right.$-CGG) (Biosearch Technologies, Novato, CA) $(100 \mu \mathrm{g})$ mixed with alum (Pierce, Rockford, IL) (100 $\mu \mathrm{l})$. In some cases, three weeks later, a second intraperitoneal injection of $\mathrm{NP}_{16}-\mathrm{CGG}(100 \mu \mathrm{g})$ was given as a boost. Mice were housed in a pathogen-free environment and all the protocols were in accordance to the rules and regulations of the Institutional Animal Care and Use Committee (IACUC) at the University of California, Irvine, CA.

\section{Immunofluorescence studies}

Spleens from immunized and non-immunized mice were embedded in optimal cutting temperature (OCT) (Sakura Finetek Inc., Torrance, CA), snap-frozen and stored at $-80^{\circ} \mathrm{C}$. Seven- $\mu \mathrm{m}$ thick cryostat sections were fixed using cold acetone and stored at $-80^{\circ} \mathrm{C}$ for 25 $\mathrm{min}$. Acetone fixed sections were then air dried for $20 \mathrm{~min}$. at room temperature. Sections were stained with fluorescein isothiocyanate (FITC)-labeled peanut agglutinin (FITC-PNA) (E-Y Laboratories, San Mateo, CA) as a GC cell marker (1:100 dilution) and kept in the dark for 1 hour, before being washed with PBS and then permeabilized using freshly prepared $0.1 \%$ Triton X-100, 0.1\% sodium citrate for $10 \mathrm{~min}$. After washing with PBS, sections were allowed to dry for $10 \mathrm{~min}$ before adding anti-mouse DRAK2 mAb conjugated with phycoerythrin (PE-anti-DRAK2 mAb) (Cell Signaling Technology Inc. Boston, MA) and allowed to incubate for 1 hour at $37^{\circ} \mathrm{C}$. Sections were then washed with PBS and viewed under a fluorescence microscope. For GC analysis, $200 \mu 1$ staining solution of PEconjugated anti-mouse CD45R (B220) mAb (RA3-6B2) (BD Biosciences, San Jose, CA), as a B cell marker (1: 200 dilution), and FITC-PNA were applied to the acetone fixed sections and kept in the dark at room temperature for 1 hour. The stained sections were washed using PBS and mounted using anti-fade reagent (Invitrogen Corp., Carlsbad, CA) for analysis. TUNEL staining was used to visualize apoptotic cells in GCs under a fluorescence microscope and was performed by first staining cryostat $7-\mu \mathrm{m}$ thick spleen sections with FITC-PNA and PE-anti-B220 mAb. Sections we incubated at room temperature for 1 hour in the dark washed with PBS and allowed to dry for $15 \mathrm{~min}$. They were then permeabilized using freshly prepared $0.1 \%$ Triton X-100 plus $0.1 \%$ sodium citrate for 10 min before being washed with PBS and allowed to dry for $10 \mathrm{~min}$. TUNEL mix (Roche Diagnostics, Basel, Switzerland) was then applied to the sections and allowed to incubate for 1 hour in $37^{\circ} \mathrm{C}$ in the dark. Sections were then washed with PBS and viewed under a fluorescence microscope. SPOT Software (Diagnostic Instruments, Inc., Sterling Heights, MI) was used to view and analyze images.

\section{In vitro B cell proliferation}

Proliferation was analyzed by CellTrace ${ }^{\mathrm{TM}}$ carboxyfluorescein succinimidyl ester (CFSE) Cell Proliferation Kit (Invitrogen Corp.). Spleen single cell suspensions were washed in Hank's balanced salt solution (HBSS) and resuspended at $1 \times 10^{6 /} \mathrm{ml}$. Resuspended cells were then incubated at $37^{\circ} \mathrm{C}$ for $10 \mathrm{~min}$., after addition of $2 \mu \mathrm{M}$ CFSE. Stained cells were suspended in ice-cold culture media, followed by a $5 \mathrm{~min}$. incubation on ice. Cells were then 
pelleted and washed by HBSS before being cultured in the presence of nil or LPS (from $E$. coli, serotype 055:B5, Sigma-Aldrich Co., St. Louis, MO) and rmIL-4 (R\&D Systems, Minneapolis, MN). After culture, B cells were harvested at different time points and analyzed using a FACSCalibur ${ }^{\mathrm{TM}}$ flow cytometer.

\section{In vivo B cell proliferation and apoptosis}

Mice were injected intraperitoneally with $\mathrm{NP}_{16}$-CGG. After seven days, they were injected with BrdU (1 mg), and again 16 hours later. Mice were then sacrificed 4 hours from the last injection. Spleen cells were stained with PE-anti-B220 mAb and FITC-PNA. Cells were then fixed and incubated with the permeablization buffer for $15 \mathrm{~min}$ in a dark at $4{ }^{\circ} \mathrm{C}$, and then stained with APC-conjugated anti-BrdU mAb using the BrdU Flow Kit (BD Biosciences). Cells were analyzed using a FACSCalibur ${ }^{\mathrm{TM}}$ flow cytometer. To measure apoptosis, B cells from immunized mice were stained with 7-amino-actinomycin D (7$\mathrm{AAD}$ ) or Annexin V (BD Biosciences) in combination with PE-anti-B220 mAb or PE-anti$\mathrm{CD} 3 \mathrm{mAb}$ and FITC-PNA and incubated for $30 \mathrm{~min}$. at $4{ }^{\circ} \mathrm{C}$ in the dark. Cells were then washed and analyzed using a FACSCalibur ${ }^{\mathrm{TM}}$ flow cytometer. TUNEL staining was also used to quantify apoptosis by counting TUNEL signals (red dots) using the SPOT Software (Diagnostic Instruments, Inc.).

\section{In vitro CSR assays}

B cells were isolated from red blood cell depleted splenocytes from non-intentionally immunized mice, and then cultured at $10^{6} \mathrm{cell} / \mathrm{ml}$ in FCS-RPMI medium with $0.05 \mathrm{mM} \beta$ mercaptoethanol. B cells were then stimulated in duplicate six plate wells with (i) nil, (ii) LPS $(10 \mu \mathrm{g} / \mathrm{ml})$, for CSR to IgG3 and (iii) LPS with rmIL-4 (2 ng/ml) for CSR to IgG1. Cells were collected on day 4 for FACS ${ }^{\circledR}$ analysis of surface Ig expression [10].

\section{PCR amplification of Ig intronic $\mathrm{V}_{\mathrm{H}} \mathrm{J558D}_{\mathrm{H}} \mathbf{4 - i E \mu} \mathrm{DNA}$}

DNA was amplified from Payer's patch $\mathrm{B}$ cells of $\mathrm{NP}_{16}-\mathrm{CGG}$ immunized mice. The intronic $\mathrm{V}_{\mathrm{H}} \mathrm{J}_{558 \mathrm{DJ}} \mathrm{H}^{4-i E \mu}$ DNA downstream of rearranged $\mathrm{V}_{\mathrm{H}} \mathrm{DJ}_{\mathrm{H}}$ was amplified using semi-nested specific PCR [29]. Primers were 5'-GCCTGACATCTGAGGACTCTGC-3' (forward) and 5'-TCTCCAGTTTCGGCTGAATCC-3' (reverse) and 5'-

TGAGACCGAGGCTAGATGCC-3' (reverse). PCR reaction conditions for the first round were $94{ }^{\circ} \mathrm{C}$ for $1 \mathrm{~min}, 58^{\circ} \mathrm{C}$ for $1.5 \mathrm{~min}, 7{ }^{\circ} \mathrm{C}$ for $2 \mathrm{~min}$ for 30 cycles, and for the secondround PCR were $94{ }^{\circ} \mathrm{C}$ for $45 \mathrm{~s}, 58^{\circ} \mathrm{C}$ for $1 \mathrm{~min}$ and $72{ }^{\circ} \mathrm{C}$ for $1 \mathrm{~min}$ for 30 cycles. Platinum Pfx DNA polymerase ${ }^{\circledR}$ (Invitrogen Corp.) was used for all DNA and cDNA amplifications. PCR products were cloned into the $\mathrm{pCR}-\mathrm{TOPO}^{\mathrm{TM}}$ vector (Invitrogen Corp.) and sequenced.

\section{Total and $\mathrm{NP}_{\mathbf{3}}$-specific IgM and IgG1 titrations}

$\mathrm{NP}_{3}$-specific IgM and IgG1, and total IgM and IgG1 levels in $\mathrm{rrak}^{-/-}$and Drak2 ${ }^{+/+}$mice were measured using specific ELISAs. Mice where immunized with $\mathrm{NP}_{16}$-CGG and boosted at day 21. Serum was collected 7 days after the boost. To measure the serum levels of $\mathrm{NP}_{3^{-}}$ specific IgM and IgG1, 96-well plates were coated with $\mathrm{NP}_{3}$-BSA. Mouse sera were diluted 1:3000 and added $100 \mu \mathrm{l}$ to the wells. After incubation at $37^{\circ} \mathrm{C}$ for 2 hours and washing, biotin-labeled anti-IgM or anti-IgG1 Ab was added to the wells for 1 hour. After a 1-hour incubation, horseradish peroxidase-labeled streptavidin was added to the wells for 1 hour. After 20 min. incubation with OPD substrate, the reaction was stopped with sulphuric acid and absorbance was measured at $492 \mathrm{~nm}$. 


\section{Results}

\section{Impaired GC development in drak2 ${ }^{-/-}$mice}

By examining the gene expression atlas of the Genomics Institute of the Novartis Research Foundation (www.expression.gnf.org), we found DRAK2 mRNA to be highly expressed in lymphoid organs, more particularly in both B and T cells. DRAK2 protein expression is highest in B220+ $\mathrm{B}$ cells, while it is nil in spleen dendritic cells (DCs) [11]. The high expression of DRAK2 in B cells of secondary lymphoid organs, specifically the spleen, has suggested a role of DRAK2 in the antibody response. To explore this possibility, we immunized mice with the TD NP 16 -CGG conjugated hapten and examined GC formation and DRAK2 expression. GCs were identified as clusters of PNA ${ }^{\text {hi }}$ cells (Figure 1A) [30, 31] or PNA ${ }^{\text {hi }} 220^{+}$cells (Figure 1B). By staining spleen sections with FITC-PNA and PE-antimouse Drak2 mAb, we found DRAK2 to be specifically expressed within GCs of wild-type, but not DRAK2-deficient, mice (Figure 1A).

To investigate the potential role of DRAK2 in GC development, we isolated spleens from mice immunized with $\mathrm{NP}_{16}$-CGG at days $0,7,10,14,18,21$ and 28 , and stained spleen sections with FITC-PNA and PE-anti-B220 mAb to analyze GC development in $d r a k 2^{-1-}$ and $\mathrm{Drak} 2^{+/+}$mice. $d r a k 2^{-/-}$GCs were normal in morphology and size, but their number was significantly reduced, about one third of that in wild-type control mice at day 14 after immunization (Figure 1B). The defective GC development was associated with a two-fold reduction in the number of GC B cells (B220 $\mathrm{PNA}^{\mathrm{hi}}$ ) in $\mathrm{drak2}^{-1-}$ mice (Figure 1C). Further, in wild-type mice, the highest GC numbers were found between days 14 and 18 (Figure 1D) [32]. In $d r a k 2^{-1-}$ mice, the GC number peaked at day 7, but this was only $50 \%$ of that in their $\mathrm{Drak2}{ }^{+/+}$littermates. Overall, $d r a k 2^{-/-}$mice showed a two- to five-fold reduction in the number of GCs. Thus, drak $2^{-1-}$ mice displayed a severely impaired GC reaction in the $\mathrm{TD}$ antibody response to $\mathrm{NP}_{16}$-CGG.

\section{drak2 $^{-/-}$B cells proliferate normally in vivo and in vitro}

Impairment of B cell proliferation has been shown to impair GC development [25, 33]. To determine whether impaired GC development in $\operatorname{drak2}^{-/-}$mice was the result of a deficiency in B cell proliferation, we performed in vitro proliferation assays using CFSElabeled B cells that were induced to proliferate by LPS or CD154 plus IL-4 [34]. These experiments revealed comparable proliferation rates in $\mathrm{drak}^{-{ }^{--}}$and $\mathrm{Drak}^{+/+} \mathrm{B}$ cells (Figure 2A, B). We also investigated B cell proliferation in vivo using BrdU incorporation in GC B cells of $\mathrm{drak2}^{-/-}$and $\mathrm{Drak}^{+/+}$mice 7 days after immunization with $\mathrm{NP}_{16}$-CGG. drak $2^{-1-} \mathrm{GC} \mathrm{B}$ cells did not display any defect in proliferation, as BrdU uptake by these cells in vivo was comparable to that of wild-type control GC B cells (Figure 2C). No BrdU uptake was observed in non-immunized control mice (data not shown). Thus, the reduction in GC numbers in $d r a k 2^{-/}$mice was not due to an intrinsic defect in B cell proliferation.

\section{drak2 $^{-/-}$mice showed impaired antibody responses to TD antigen}

GCs are critical for the production and the affinity maturation of antibodies [35, 36]. We hypothesized that the impaired GC formation in $d \mathrm{rak}^{-/-}$mice would result in impaired production of high affinity antibodies in these mice. To test this hypothesis, we collected sera from $\mathrm{NP}_{16}$-CGG immunized $\mathrm{rrak}^{-{ }^{--}}$and $\mathrm{Drak}^{+/+}$mice at day 28 , after a booster injection at day 21 , and measured the ability of $\operatorname{IgM}$ and $\mathrm{IgG} 1$ antibodies to bind $\mathrm{NP}_{3}$ as well as, the serum concentration of total IgM and IgG1. In $\mathrm{rrak2}^{-1-}$ mice, the total serum level of IgM was comparable to their wild-type littermates; however, in these mice, the total IgG1 serum level was significantly reduced (Figure 3 ). Moreover, $d r a k 2^{-1-}$ mice showed significantly lower binding affinity of $\mathrm{IgG} 1$ to $\mathrm{NP}_{3}$. Thus, DRAK2 activity is essential for sustaining the $\mathrm{GC}$ reaction necessary for the generation of high affinity antibodies. 


\section{drak2 $^{-/-}$B cells display normal SHM and CSR}

Immunoglobulin (Ig) SHM and CSR occur in GCs. Both mechanisms play critical roles in the development of efficient and mature antibody responses [37, 38]. SHM introduces pointmutations at a very high rate (10 ${ }^{-3}$ base pair/cell division) in Ig V(D)J DNA [29, 39-41], thereby providing the substrate for selection of high affinity mutants by the antigen driving of the antibody response (affinity maturation). CSR diversifies the effector functions of the antibody by replacing $\mathrm{C} \mu$ exons with $\mathrm{C} \gamma, \mathrm{C} \alpha$ or $\mathrm{C} \varepsilon$ exons, thereby converting $\operatorname{IgM}$ to $\operatorname{Ig} \mathrm{A}$, $\operatorname{IgG}$ or $\operatorname{IgE}[29,42-44]$.

We wanted to determine whether the defective production of high affinity antibodies in drak $2^{-1-}$ mice, was a result of impaired SHM. To this end, we analyzed the $\mathrm{J}_{\mathrm{H}} 4-\mathrm{iE} \mu$ intronic region DNA and evaluated the frequency of mutations [29, 39, 40, 45, 46]. Point-mutations in this region reflect the intrinsic activity of SHM, and a decreased mutation frequency in this region stems from a defective SHM machinery [29]. The analysis of iE $\mu$ DNA showed that the frequency of mutations in $d r a k 2^{-/-}$mice was comparable to that of $D r a k 2^{+/+}$mice, suggesting that SHM in DRAK2-deficient B cells was functionally normal (Figure 4A). To determine whether the reduction in the overall IgG1 serum levels in $d \mathrm{rak}^{-1-}$ mice resulted from a defective CSR machinery, we performed in vitro CSR assays on splenocytes harvested from non-immunized $\mathrm{rrak}^{-{ }^{--}}$and $\mathrm{Drak}^{+/+}$activated in vitro with LPS and IL-4. We found that $d r a k 2^{-/}$B cells displayed a CSR activity comparable to that of their wild-type counterparts (Figure 4B). Thus, DRAK2-deficient B cells display functional SHM and CSR, indicating that the defective high affinity IgG1 antibody production in $\mathrm{drak}^{-{ }^{-}}$ mice does not result from defects in these machineries.

\section{GC B cells in drak2 ${ }^{-1-}$ mice display increased apoptosis}

Apoptosis plays critical roles in GC development and homeostasis [33, 38, 47, 48]. Since drak $2^{-1}$ B cell proliferation was found to be normal, we hypothesized that GC B cell survival is impaired in these mice. To test this hypothesis, we harvested $\mathrm{B}$ cells from $\mathrm{NP}_{16^{-}}$ CGG immunized $\mathrm{drak}^{-/-}$and $\mathrm{Drak} 2^{+/+}$mice and stained them with Annexin-V for FACS analysis. drak2 $2^{-1-}$ mice showed increased total B cell apoptosis (Figure 5A). We also analyzed GC B cell apoptosis by staining with PE-anti-mouse B220 mAb, FITC-PNA and 7AAD spleen B cells from $\mathrm{rrak}^{-{ }^{--}}$and $\mathrm{Drak}^{+/+}$mice 10 and 14 days after $\mathrm{NP}_{16}$-CGG immunization. B220 $\mathrm{PNA}^{\text {hi }}(\mathrm{GC}) \mathrm{B}$ cells from $\operatorname{drak}^{-1-}$ mice showed a higher degree of apoptosis than their wild-type counterparts (Figure 5B). To directly visualize apoptotic B cells in the GC, we stained with PE-anti-mouse B220 mAb, FITC-PNA and Texas redTUNEL spleen sections from $d r a k 2^{-/-}$and $\mathrm{Drak}^{+/+}$mice 7 days after immunization with $\mathrm{NP}_{16}$-CGG. TUNEL signals (red dots, indicators of apoptosis) showed that $d \mathrm{rak}^{-/-}$mice displayed a three-fold increase in the GC B cell apoptosis as compared to their wild-type littermates (Figure 5C, D). Such an increased apoptosis was almost entirely due to apoptosis of light zone GC B cells, as suggested by their proximity to the T cell zone [49].

\section{Increased GC T cell apoptosis in drak2 ${ }^{-/-}$mice}

$T_{h}$ cells contribute to B cell survival in the GC by engaging CD40 on B cells with CD154 $[17,19,50]$. Two-photon microscopy has shown that B cells establish stable contacts with $T$ cells in the GC during the immune response [49, 51]. Also, B and T cells have frequent encounters and $\mathrm{T}$ cells carry fragments of dead B cells, suggesting that $\mathrm{T}$ cells play a more dominant role in GC B cell selection than previously thought, and indicating that $\mathrm{T}$ cells are critical for B cell survival in the GC [51]. DRAK2 is highly expressed in T cells and, as we have shown above, B cells undergo increased apoptosis in $\mathrm{rrak}^{-{ }^{-}}$mice. Moreover, drak $2^{-/-} \mathrm{T}$ cells exhibit enhanced apoptosis in autoimmune EAE mice [12]. We hypothesized that GC T cells will also display a high rate of apoptosis. Consistent with this hypothesis, activated $\mathrm{T}$ cells from $d r a k 2^{-/-} \mathrm{T}$ cells have been found to be hypersensitive to 
apoptosis (Ramos et al, manuscript submitted). To test our hypothesis, we harvested $\mathrm{T}$ cells

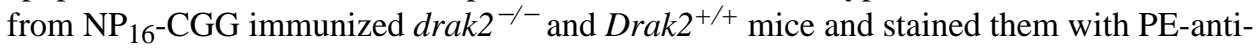
CD3 mAb, FITC-PNA and APC-7-AAD. FACS analysis of these stained cells showed increased $\mathrm{T}$ cell apoptosis in GCs of $d r a k 2^{-/-}$mice (Figure 6A).

\section{T cell survival induced by enforced $B c l-X_{L}$ expression rescues $B$ cells from apoptosis, restores GC formation and corrects the TD antibody response to $\mathrm{NP}_{16}-\mathrm{CGG}$ in drak2 ${ }^{-1-}$ mice}

To determine whether B cell apoptosis in $d r a k 2^{-/-}$mice is secondary to increased $\mathrm{T}$ cell apoptosis, we immunized mice bearing a $B c l-x L$ transgene that was specifically expressed in T cells [28] crossed onto the $d r a k 2^{-/-}$background ( $\mathrm{rak}^{-/-\operatorname{tg} B c l-x L}$ mice) (Ramos et al, manuscript submitted). $d r a k 2^{-1-\operatorname{tg} B c l-x L}$ mice and their Drak2 $2^{+/+} \operatorname{tg} B c l-x L$ counterparts were immunized with $\mathrm{NP}_{16}-\mathrm{CGG}$ and spleens were harvested 14 days after immunization for

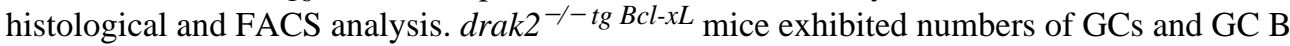
cells comparable to those in Drak2 $2^{+/+} \operatorname{tg} B c l-x L$ mice (Figure 6B, C), suggesting a rescue of drak $2^{-/}$GC B cells upon enforced expression of anti-apoptotic protein Bcl-xL in T cells [25]. Accordingly, TUNEL analysis showed that cell apoptosis in $d r a k 2^{-1-\operatorname{tg} B c l-x L} \mathrm{GCs}$ was not higher than that in $D r a k 2^{+/+} \operatorname{tg} B c l-x L$ mice (Figure 7A, B). We then measured B cell apoptosis using Annexin- $\mathrm{V}$ and also found that $\mathrm{B}$ cells in $d r a k 2^{-/-\operatorname{tg} B c l-x L}$ mice exhibited apoptosis to a degree not higher than that of B cells in Drak2 $2^{+/+\operatorname{tg} B c l-x L}$ mice (Figure 7C). To determine whether the $\mathrm{T}$ cell-dependent rescue of $\mathrm{B}$ cell apoptosis also rescued the antibody response to $\mathrm{TD} \mathrm{NP}_{16}$-CGG, we analyzed total and $\mathrm{NP}_{3}$-binding IgM and IgG1 in mice that had been injected with $\mathrm{NP}_{16}$-CGG 28 days before, and boosted 21 days after the initial injection. The total IgG1 serum level in $d r a k 2^{-1-t g B c l-x L}$ mice was restored to near normal level, virtually comparable to that in $\mathrm{Drak}^{+/+} \operatorname{tg} B c l-x L$ littermates. Accordingly, enforced expression of $B c l-x L$ in $d r a k 2^{-/-} \mathrm{GC}$ T cells completely restored or significantly raised the level of high affinity $\mathrm{NP}_{3}$-binding IgG1 (Figures 3 and 8). Thus, increased intrinsic T cell apoptosis was responsible for the lower number of GCs and GC B cells, and the defective TD antibody response in $d r a k 2^{-/-}$mice ( $\left.\mathrm{p}>0.05\right)$.

\section{Discussion}

Proteins in the DAP family regulate apoptosis in many cell types. DRAK2, one of the DAP family members, is highly expressed in both B and T lymphocytes [11]. Its role in T cells has been studied extensively. However, the function of DRAK2 in B cells and its role in the humoral immune response have not been investigated. Also, the mechanisms that regulate DRAK2 functions and its substrates are still to be identified. We have shown that DRAK2 is specifically expressed in the GC. We have also shown here that $\mathrm{rrak}^{-{ }^{--}}$mice exhibit impaired GC development. We initially speculated that this defect might be a result of impaired B cell proliferation, since B cell proliferation is critical during the early stages of $\mathrm{GC}$ formation. However, we found no intrinsic defect in $\mathrm{drak}^{-1-} \mathrm{B}$ cell proliferation in vivo or in vitro, leading us to hypothesize that the impairment in $\mathrm{GC}$ formation in $d \mathrm{rak}^{-/-}$mice may be a result of defect(s) in later stages of the GC reaction.

The unique dynamics and structure of the GC are critical for the maturation of the antibody response. Thus, impairment in GC development might result in an impaired antibody response in $d r a k 2^{-1-}$ mice. Indeed, we found that, when compared to their wild-type littermates, $d \mathrm{rak}^{-/-}$mice displayed a more than $35 \%$ reduction in total IgG1 serum levels and about $75 \%$ reduction in high affinity antibodies against $\mathrm{NP}_{3}$. This defect in generating high affinity IgGs was not due to inherent defects in the SHM and CSR machineries, as we found both SHM and CSR to be inherently functional in $\mathrm{rrak}^{-1-} \mathrm{B}$ cells and $d \mathrm{rak} 2^{-1-}$ mice. This led us to conclude that in these mice, the decrease in total IgG1 serum level and 
high affinity $\mathrm{NP}_{3}$-binding IgG1 was the result of increased apoptosis of $\mathrm{B}$ cells, and thereby, a defective positive selection, in the GC.

Apoptosis is important for the development, maintenance and effector functions of the immune system [33]. It is crucial in the GC reaction and disruption of the mechanisms that regulate B cell apoptosis results in GC hyperplasia and impaired antibody responses [48]. We have shown that the proportion of spleen B cells undergoing apoptosis was higher in drak $2^{-1-}$ mice when compared to their wild-type littermates. However, increased total B cell apoptosis in the spleen does not necessary implies an increased GC B cell apoptosis. Therefore, we have further quantified apoptotic B cells in the GC and shown that the number of GC B cells undergoing apoptosis in $\mathrm{drak}^{-/-}$mice was significantly higher than their wild-type counterparts during days 10 through 14 post-NP ${ }_{16}$-CGG immunization. These findings were informative, but limited, in that they did not specifically show where in the GC B cells were undergoing apoptosis. Our TUNEL staining results suggested that apoptotic B cell were localized in an area that likely identifies the GC light zone, where B cells displaying a mutated, high affinity BCR are positively selected [49].

The GC is an elaborate microenvironment of cellular interaction and the complex nature of such interactions is critical to their development and function. B cells make up $95 \%$ and $\mathrm{T}$ cells make up 2-3\% of the total GC cell population. DRAK2 expression in both cell types makes the role of this signaling molecule important during a humoral response and $\mathrm{T}$ and $\mathrm{B}$ cell interactions in the GC reaction. $\mathrm{GC} \mathrm{T}_{\mathrm{h}}$ cells are important in stimulating B cells to undergo SHM and CSR and differentiate into memory and plasma cells, and are likely involved in B cell positive selection [17, 52]. A pathway for B cell selection in the GC would entail T cell interactions with B cells (centrocytes) via gp39 and CD40 [18, 53]. Failure of $B$ cells to receive $T_{h}$ cell signals has been thought to result in their apoptosis. However, to date, there has been no conclusive evidence showing $\mathrm{T}_{\mathrm{h}}$ cell involvement in the positive selection during the GC reaction. Imaging studies using the two-photon microscopy have suggested that $\mathrm{T}$ cells play a major role in $\mathrm{B}$ cell positive selection during an immune response, a conclusion reached by observing $\mathrm{T}$ cells forming stable contacts with $\mathrm{B}$ cells $[49,51]$. Our findings have provided the first indication that increased $\mathrm{T}$ cell apoptosis leads to an abnormal B cell apoptosis in the GC, which, in turn, would lead to a defective positive selection in a TD antibody response.

As we have shown here, deficiency in DRAK2 results in increased B cell apoptosis in the GC and decreased numbers of GCs. We contended that apoptosis would also occur in GC T cells. Indeed, we have found that the proportion of T cell undergoing apoptosis in the GC of DRAK2-deficient mice is significantly higher than that of their wild-type controls. Further, we asked the question whether the increased B cell apoptosis in the GC of $d r a k 2^{-/-}$mice is inherent to $\mathrm{B}$ cells or is due to lack of $\mathrm{T}$ cell stimulation. We have shown here that specific overexpression of anti-apoptotic protein Bcl-xLin $d r a k 2^{-1-} \mathrm{T}$ cells prevented $\mathrm{T}$ cell apoptosis [28] in GCs and restored the numbers of GCs and GC B cells in $d r a k 2^{-1-\operatorname{tg} B c l-x L}$ mice. Indeed, the proportion of B cell undergoing apoptosis in $d r a k 2^{--t g B c l-x L}$ mice was comparable to Drak2 $2^{+/} \operatorname{tg} B c l-x L$ mice. TUNEL staining has also showed that GC B cell apoptosis in $\mathrm{drak}^{-1-\operatorname{tg} B c l-x L}$ mice was normal, that is, comparable to $\mathrm{Drak2} 2^{+/+\operatorname{tg} B c l-x L}$ mice. These findings led us to conclude that, in $\mathrm{drak}^{-1-}$ mice, rescue of $\mathrm{T}$ cells from apoptosis leads to rescue of GC development and prevents B cells from undergoing apoptosis.

In drak $^{-/-}$mice, $\mathrm{T}$ cells failed to support B cell survival and selection in the GC, leading to an abortive $\mathrm{GC}$ reaction and an impaired antibody response to $\mathrm{NP}_{16}$-CGG. The GC rescue in

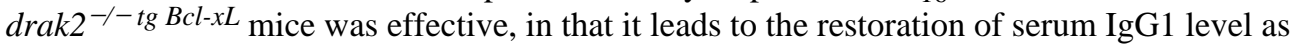
well as the high affinity $\mathrm{IgG1}$ response to $\mathrm{NP}_{3}$. Thus, rescue of $\mathrm{T}$ cells from apoptosis 
allowed for a restoration of positive selection of affinity matured IgG1 antibodies. In conclusion, our findings show that $d r a k 2^{-1-}$ B cells are inherently normal in SHM and CSR. They also demonstrate that by allowing for T cell survival, DRAK2 is critical for fostering and supporting an optimal GC reaction and the maturation of a high affinity class switched antibody response. Finally, they suggest that $\mathrm{T}$ cells play an important role in GC lymphocyte selection, possibly by providing, in combination with FDCs, secondary signals that are critical in preventing B cells with high affinity BCRs from undergoing apoptosis $[49,51,54-57]$.

\section{Acknowledgments}

This work was supported by N.I.H. grants AI 45011 and AI 60573 to P.C., and AI 63419 to C.M.W.

We thank Dr. Zsuzsanna Pal, Stephanie Ramos and Jennifer Hernandez for their invaluable discussions.

\section{References}

1. Sanjo H, Kawai T, Akira S. DRAKs, novel serine/threonine kinases related to death-associated protein kinase that trigger apoptosis. J Biol Chem. 1998; 273:29066-29071. [PubMed: 9786912]

2. Kawai T, Nomura F, Hoshino K, Copeland NG, Gilbert DJ, Jenkins NA, Akira S. Death-associated protein kinase 2 is a new calcium/calmodulin-dependent protein kinase that signals apoptosis through its catalytic activity. Oncogene. 1999; 18:3471-3480. [PubMed: 10376525]

3. Kogel D, Prehn JH, Scheidtmann KH. The DAP kinase family of pro-apoptotic proteins: novel players in the apoptotic game. Bioessays. 2001; 23:352-358. [PubMed: 11268041]

4. Kissil JL, Feinstein E, Cohen O, Jones PA, Tsai YC, Knowles MA, Eydmann ME, Kimchi A. DAPkinase loss of expression in various carcinoma and B-cell lymphoma cell lines: possible implications for role as tumor suppressor gene. Oncogene. 1997; 15:403-407. [PubMed: 9242376]

5. Friedrich ML, Wen BG, Bain G, Kee BL, Katayama C, Murre C, Hedrick SM, Walsh CM. DRAK2, a lymphoid-enriched DAP kinase, regulates the TCR activation threshold during thymocyte selection. Int Immunol. 2005; 17:1379-1390. [PubMed: 16172133]

6. Matsumoto M, Miyake Y, Nagita M, Inoue H, Shitakubo D, Takemoto K, Ohtsuka C, Murakami H, Nakamura N, Kanazawa H. A serine/threonine kinase which causes apoptosis-like cell death interacts with a calcineurin B-like protein capable of binding $\mathrm{Na}(+) / \mathrm{H}(+)$ exchanger. J Biochem (Tokyo). 2001; 130:217-225. [PubMed: 11481038]

7. Kuwahara H, Nakamura N, Kanazawa H. Nuclear Localization of the Serine/Threonine Kinase DRAK2 Is Involved in UV-Induced Apoptosis. Biol Pharm Bull. 2006; 29:225-233. [PubMed: 16462023]

8. Friedrich ML, Cui M, Hernandez JB, Weist BM, Andersen HM, Zhang X, Huang L, Walsh CM. Modulation of DRAK2 autophosphorylation by antigen receptor signaling in primary lymphocytes. J Biol Chem. 2007; 282:4573-4584. [PubMed: 17182616]

9. Raveh T, Droguett G, Horwitz MS, DePinho RA, Kimchi A. DAP kinase activates a p19ARF/p53mediated apoptotic checkpoint to suppress oncogenic transformation. Nat Cell Biol. 2001; 3:1-7. [PubMed: 11146619]

10. Mao J, Qiao X, Luo H, Wu J. Transgenic drak2 overexpression in mice leads to increased T cell apoptosis and compromised memory T cell development. J Biol Chem. 2006; 281:12587-12595. [PubMed: 16517594]

11. McGargill MA, Wen BG, Walsh CM, Hedrick SM. A deficiency in Drak2 results in a T cell hypersensitivity and an unexpected resistance to autoimmunity. Immunity. 2004; 21:781-791. [PubMed: 15589167]

12. Ramos SJ, Hardison JL, Stiles LN, Lane TE, Walsh CM. Anti-viral effector T cell responses and trafficking are not dependent upon DRAK2 signaling following viral infection of the central nervous system. Autoimmunity. 2007; 40:54-65. [PubMed: 17364498]

13. Schaumburg CS, Gatzka M, Walsh CM, Lane TE. DRAK2 regulates memory T cell responses following murine coronavirus infection. Autoimmunity. 2007; 40:483-488. [PubMed: 17966037] 
14. Meyer-Hermann M, Beyer T. The type of seeder cells determines the efficiency of germinal center reactions. Bull Math Biol. 2004; 66:125-141. [PubMed: 14670533]

15. Marinova E, Han S, Zheng B. Human germinal center T cells are unique Th cells with high propensity for apoptosis induction. Int Immunol. 2006; 18:1337-1345. [PubMed: 16798841]

16. Liu YJ, Johnson GD, Gordon J, MacLennan IC. Germinal centres in T-cell-dependent antibody responses. Immunol Today. 1992; 13:17-21. [PubMed: 1739427]

17. McHeyzer-Williams LJ, Malherbe LP, McHeyzer-Williams MG. Helper T cell-regulated B cell immunity. Curr Top Microbiol Immunol. 2006; 311:59-83. [PubMed: 17048705]

18. MacLennan IC. Germinal centers. Annu Rev Immunol. 1994; 12:117-139. [PubMed: 8011279]

19. Manser T. Textbook germinal centers? J Immunol. 2004; 172:3369-3375. [PubMed: 15004133]

20. Hur DY, Kim DJ, Kim S, Kim YI, Cho D, Lee DS, Hwang Y, Bae K, Chang KY, Lee WJ. Role of follicular dendritic cells in the apoptosis of germinal center B cells. Immunol Lett. 2000; 72:107111. [PubMed: 10841945]

21. Hoch S, Boyd M, Malone B, Gonye G, Schwaber J, Schwaber J. Fas-mediated apoptosis eliminates B cells that acquire self-reactivity during the germinal center response to NP. Cell Immunol. 2000; 203:103-110. [PubMed: 11006008]

22. Tsunoda R, Heinen E, Sugai N. Follicular dendritic cells in vitro modulate the expression of Fas and Bcl-2 on germinal center B cells. Cell Tissue Res. 2000; 299:395-402. [PubMed: 10772253]

23. Kelsoe G. The germinal center: a crucible for lymphocyte selection. Semin Immunol. 1996; 8:179_ 184. [PubMed: 8738917]

24. Kelsoe G. Life and death in germinal centers (redux). Immunity. 1996; 4:107-111. [PubMed: 8624801]

25. Tarlinton DM, Smith KG. Dissecting affinity maturation: a model explaining selection of antibodyforming cells and memory B cells in the germinal centre. Immunol Today. 2000; 21:436-441. [PubMed: 10953095]

26. Phan TG, Paus D, Chan TD, Turner ML, Nutt SL, Basten A, Brink R. High affinity germinal center B cells are actively selected into the plasma cell compartment. J Exp Med. 2006; 203:24192424. [PubMed: 17030950]

27. Meyer-Hermann ME, Maini PK. Cutting edge: back to “one-way” germinal centers. J Immunol. 2005; 174:2489-2493. [PubMed: 15728453]

28. Chao DT, Linette GP, Boise LH, White LS, Thompson CB, Korsmeyer SJ. Bcl-XL and Bcl-2 repress a common pathway of cell death. J Exp Med. 1995; 182:821-828. [PubMed: 7650488]

29. Zan H, Shima N, Xu Z, Al-Qahtani A, Evinger AJ lii, Zhong Y, Schimenti JC, Casali P. The translesion DNA polymerase theta plays a dominant role in immunoglobulin gene somatic hypermutation. Embo J. 2005; 24:3757-3769. [PubMed: 16222339]

30. Rose ML, Birbeck MS, Wallis VJ, Forrester JA, Davies AJ. Peanut lectin binding properties of germinal centres of mouse lymphoid tissue. Nature. 1980; 284:364-366. [PubMed: 7360273]

31. Kraal G, Weissman IL, Butcher EC. Germinal centre B cells: antigen specificity and changes in heavy chain class expression. Nature. 1982; 298:377-379. [PubMed: 6806671]

32. Wang Y, Carter RH. CD19 regulates B cell maturation, proliferation, and positive selection in the FDC zone of murine splenic germinal centers. Immunity. 2005; 22:749-761. [PubMed: 15963789]

33. Opferman JT, Korsmeyer SJ. Apoptosis in the development and maintenance of the immune system. Nat Immunol. 2003; 4:410-415. [PubMed: 12719730]

34. Ettinger R, Sims GP, Fairhurst AM, Robbins R, da Silva YS, Spolski R, Leonard WJ, Lipsky PE. IL-21 induces differentiation of human naive and memory B cells into antibody-secreting plasma cells. J Immunol. 2005; 175:7867-7879. [PubMed: 16339522]

35. Moreira JS, Faro J. Modelling two possible mechanisms for the regulation of the germinal center dynamics. J Immunol. 2006; 177:3705-3710. [PubMed: 16951330]

36. Meyer-Hermann M. A mathematical model for the germinal center morphology and affinity maturation. J Theor Biol. 2002; 216:273-300. [PubMed: 12183119]

37. Rundell A, DeCarlo R, HogenEsch H, Doerschuk P. The humoral immune response to Haemophilus influenzae type b: a mathematical model based on T-zone and germinal center B-cell dynamics. J Theor Biol. 1998; 194:341-381. [PubMed: 9778443] 
38. Wolniak KL, Shinall SM, Waldschmidt TJ. The germinal center response. Crit Rev Immunol. 2004; 24:39-65. [PubMed: 14995913]

39. Casali P, Pal Z, Xu Z, Zan H. DNA repair in antibody somatic hypermutation. Trends Immunol. 2006; 27:313-321. [PubMed: 16737852]

40. Xu Z, Zan H, Pal Z, Casali P. DNA replication to aid somatic hypermutation. Adv Exp Med Biol. 2007; 596:111-127. [PubMed: 17338180]

41. Neuberger MS, Di Noia JM, Beale RC, Williams GT, Yang Z, Rada C. Somatic hypermutation at A. T pairs: polymerase error versus dUTP incorporation. Nat Rev Immunol. 2005; 5:171-178. [PubMed: 15688043]

42. Casali P, Zan H. Class switching and Myc translocation: how does DNA break? Nat Immunol. 2004; 5:1101-1103. [PubMed: 15496946]

43. Xu Z, Fulop Z, Zhong Y, Evinger AJ 3rd, Zan H, Casali P. DNA lesions and repair in immunoglobulin class switch recombination and somatic hypermutation. Ann N Y Acad Sci. 2005; 1050:146-162. [PubMed: 16014529]

44. Zan H, Wu X, Komori A, Holloman WK, Casali P. AID-dependent generation of resected doublestrand DNA breaks and recruitment of Rad52/Rad51 in somatic hypermutation. Immunity. 2003; 18:727-738. [PubMed: 12818155]

45. Diaz M, Verkoczy LK, Flajnik MF, Klinman NR. Decreased frequency of somatic hypermutation and impaired affinity maturation but intact germinal center formation in mice expressing antisense RNA to DNA polymerase zeta. J Immunol. 2001; 167:327-335. [PubMed: 11418667]

46. Kimoto H, Nagaoka H, Adachi Y, Mizuochi T, Azuma T, Yagi T, Sata T, Yonehara S, Tsunetsugu-Yokota Y, Taniguchi M, Takemori T. Accumulation of somatic hypermutation and antigen-driven selection in rapidly cycling surface Ig+ germinal center (GC) B cells which occupy GC at a high frequency during the primary anti-hapten response in mice. Eur J Immunol. 1997; 27:268-279. [PubMed: 9022029]

47. Liu YJ, Arpin C. Germinal center development. Immunol Rev. 1997; 156:111-126. [PubMed: 9280752]

48. van Eijk M, Defrance T, Hennino A, de Groot C. Death-receptor contribution to the germinalcenter reaction. Trends Immunol. 2001; 22:677-682. [PubMed: 11738998]

49. Allen CD, Ansel KM, Low C, Lesley R, Tamamura H, Fujii N, Cyster JG. Germinal center dark and light zone organization is mediated by CXCR4 and CXCR5. Nat Immunol. 2004; 5:943-952. [PubMed: 15300245]

50. Hennino A, Berard M, Krammer PH, Defrance T. FLICE-inhibitory protein is a key regulator of germinal center B cell apoptosis. J Exp Med. 2001; 193:447-458. [PubMed: 11181697]

51. Allen CD, Okada T, Tang HL, Cyster JG. Imaging of germinal center selection events during affinity maturation. Science. 2007; 315:528-531. [PubMed: 17185562]

52. Zan H, Li Z, Yamaji K, Dramitinos P, Cerutti A, Casali P. B cell receptor engagement and T cell contact induce Bcl-6 somatic hypermutation in human B cells: identity with Ig hypermutation. J Immunol. 2000; 165:830-839. [PubMed: 10878357]

53. Cerutti A, Zan H, Schaffer A, Bergsagel L, Harindranath N, Max EE, Casali P. CD40 ligand and appropriate cytokines induce switching to $\mathrm{IgG}, \operatorname{IgA}$, and $\mathrm{IgE}$ and coordinated germinal center and plasmacytoid phenotypic differentiation in a human monoclonal $\operatorname{IgM}+\operatorname{IgD}+\mathrm{B}$ cell line. $\mathrm{J}$ Immunol. 1998; 160:2145-2157. [PubMed: 9498752]

54. Estes JD, Thacker TC, Hampton DL, Kell SA, Keele BF, Palenske EA, Druey KM, Burton GF. Follicular dendritic cell regulation of CXCR4-mediated germinal center CD4 T cell migration. J Immunol. 2004; 173:6169-6178. [PubMed: 15528354]

55. Park CS, Yoon SO, Armitage RJ, Choi YS. Follicular dendritic cells produce IL-15 that enhances germinal center B cell proliferation in membrane-bound form. J Immunol. 2004; 173:6676-6683. [PubMed: 15557159]

56. Schmidt-Supprian M, Tian J, Ji H, Terhorst C, Bhan AK, Grant EP, Pasparakis M, Casola S, Coyle AJ, Rajewsky K. I kappa B kinase 2 deficiency in T cells leads to defects in priming, B cell help, germinal center reactions, and homeostatic expansion. J Immunol. 2004; 173:1612-1619. [PubMed: 15265889] 
57. Allen CD, Okada T, Cyster JG. Germinal-center organization and cellular dynamics. Immunity. 2007; 27:190-202. [PubMed: 17723214] 

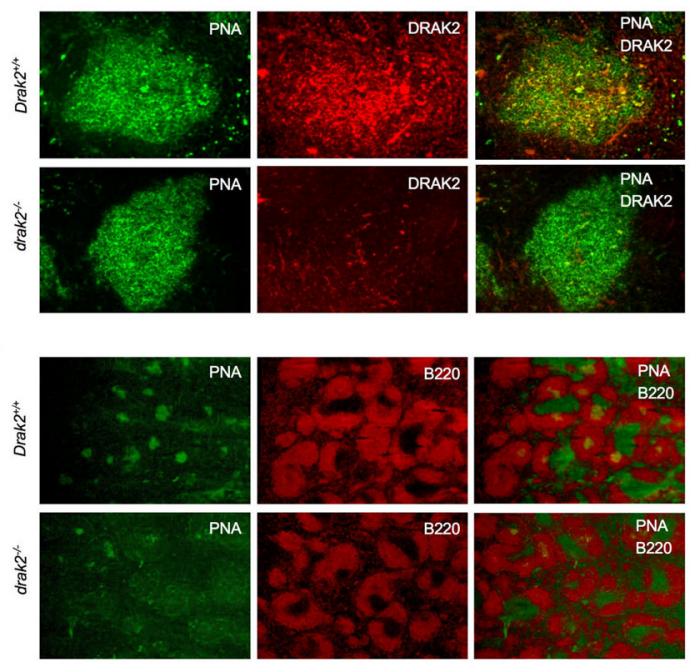

C

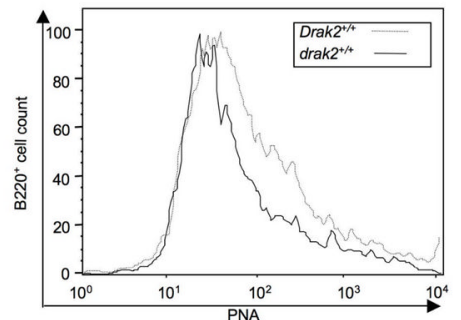

D

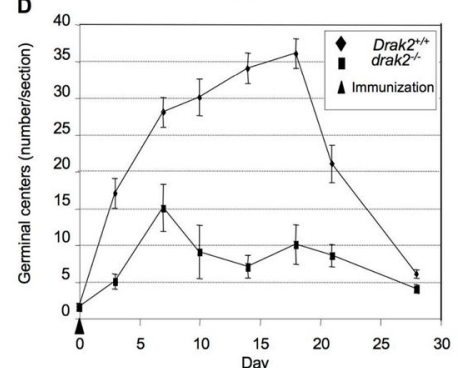

Figure 1.

Impaired GC development in $d r a k 2^{-/-}$mice. (A) Spleen sections from $d r a k 2^{-/-}$and Drak $2^{+/+}$mice 14 days after $\mathrm{NP}_{16}$-CGG immunization were stained with FITC-PNA and PE-anti-DRAK2 mAb. Immunofluorescence microscopy showed expression of DRAK2 protein in GCs of $\mathrm{Drak}^{+/+}$mice, but not $\mathrm{rrak}^{-/-}$mice (original magnification: 200×). (B) Spleen sections from $\mathrm{drak}^{-/-}$and $\mathrm{Drak}^{+/+}$mice 14 days after $\mathrm{NP}_{16}$-CGG immunization were stained with FITC-PNA and PE-anti-B220 mAb, and subjected to immunofluorescence microscopy. The number of GCs (B220 ${ }^{+} \mathrm{PNA}^{\text {hi }}$ ) was determined by counting visible GCs under the microscope. In each spleen section, the number GCs was smaller in $d r a k 2^{-1-}$ mice than in $\mathrm{Drak2}^{+/+}$mice (original magnification: 40x). (C) FACS analysis of the number of $\mathrm{B} 220^{+} \mathrm{PNA}^{\text {hi }}$ cells showed a two-fold decrease in the number of GC B cells in $d r a k 2^{-/-}$ mice as compared to $\mathrm{Drak2}^{+/+}$mice 14 days after $\mathrm{NP}_{16}$-CGG immunization. (D) Number of GCs per spleen section in $\mathrm{drak2}^{-/-}$and $\mathrm{Drak2}^{+/+}$mice at different days after $\mathrm{NP}_{16}-\mathrm{CGG}$ immunization. 
A

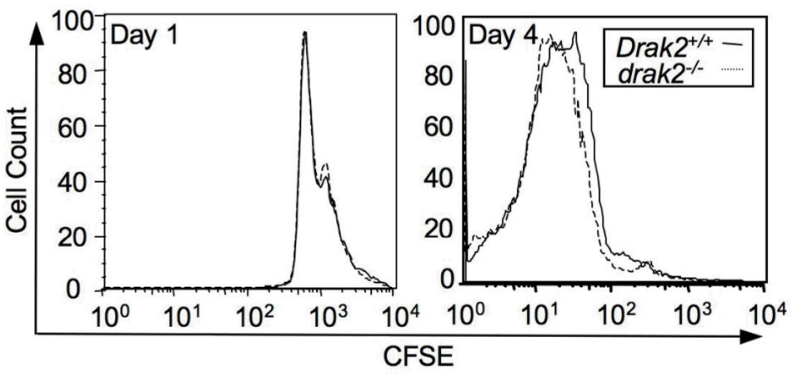

B
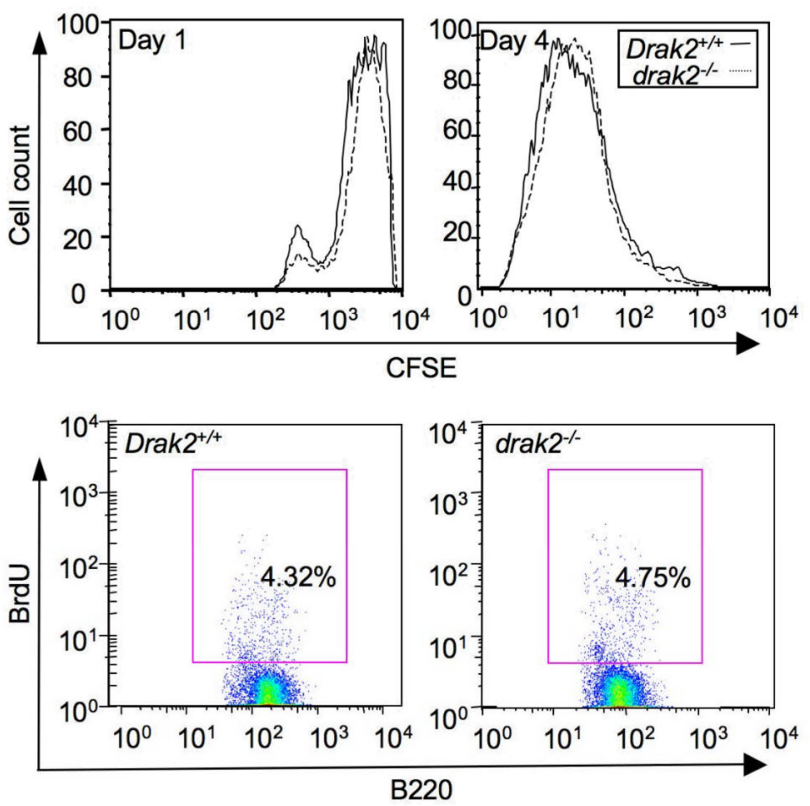

Figure 2.

Normal proliferation of $d r a k 2^{-/-} \mathrm{B}$ cell in vitro and in vivo. Spleen B cells from drak2 $2^{-1-}$ mice were cultured with LPS plus IL-4 (A) or CD154 plus IL-4 (B) after being labeled with CFSE to track their division. After 1, 2, 3 and 4 days of culture, cells were harvested and analyzed by flow cytometry. Peaks represent sequential halvings of CFSE fluorescence and reflect cell divisions. $d r a k 2^{-/-}$and $\operatorname{rrak}^{+/+} \mathrm{B}$ cells exhibited a similar CFSE pattern, indicating B cells proliferation is not defective. (C) Cell proliferation in vivo, as analyzed by BrdU incorporated in $\mathrm{B} 220^{+} \mathrm{PNA}^{\text {hi }} \mathrm{GC}$ B cells from spleen of $\mathrm{NP}_{16}-\mathrm{CGG}$ immunized mice. Seven days after immunization, mice were injected twice with BrdU within 16 hours and sacrificed 4 hours after the second injection. Spleen cells were stained with PE- anti-mouse B220 mAb, FITC-PNA and APC-anti-BrdU mAb. No significant difference was observed in the number of BrdU-positive B220 $\mathrm{PNA}^{\text {hi }} \mathrm{GC}$ B cells from $\mathrm{rrak}^{-{ }^{--}}$and $\mathrm{Drak2} 2^{+/+}$mice. 

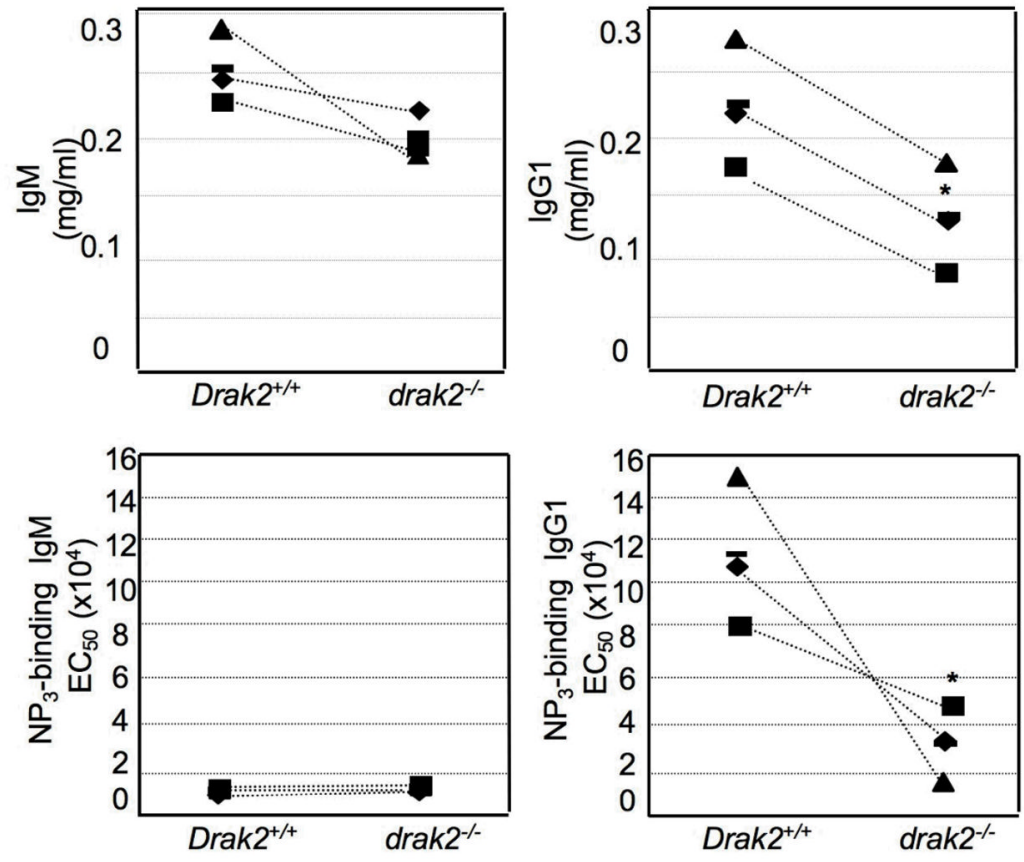

Figure 3.

Impaired antibody response to TD antigen in $\mathrm{rak}^{-/-}$mice. Mice were immunized with $\mathrm{NP}_{16}$-CGG at day 0 and then given a booster injection on day 21 . Sera were collected at day 28 and analyzed for total and NP-specific IgM and IgG1. $\mathrm{NP}_{3}$-BSA was used to capture high affinity IgM and IgG1. Total IgG1 and high-affinity $\mathrm{NP}_{3}$-specific IgG1 levels in drak $^{-/-}$ mice were significant lower as compared to their wild-type littermates $(* p<0.005)$. The reduction in total and $\mathrm{NP}_{3}$-specific IgG1 levels reflected decreased class switching to IgG1as well as impaired positive selection of high affinity mutants. 

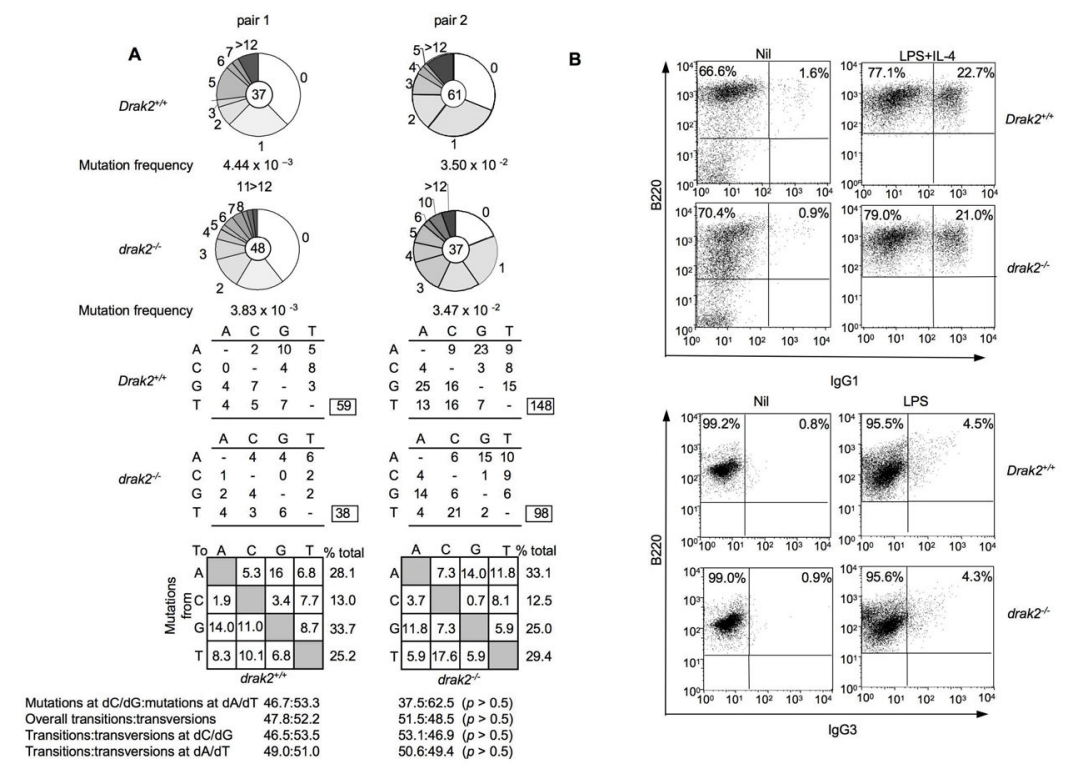

Figure 4.

Normal SHM and CSR in $d r a k 2^{-/-}$mice and $d r a k 2^{-/-}$B cells. (A) The mouse $\mathrm{J}_{\mathrm{H}} 4-\mathrm{iE} \mu$ intronic region DNA was amplified from Peyer's patch B cells and subjected to sequence analysis. Pie charts depict the proportions of sequences that carry $1,2,3$, etc. mutations over the $560 \mathrm{bp}$ DNA sequence analyzed. The numbers of the sequences analyzed are at the center of the pies. The mutation frequency in $\mathrm{rrak}^{-{ }^{--}}$was comparable to that in $\mathrm{Drak} 2^{+/+}$ mice $(p=0.30)$. (B) In vitro CSR in B cells from spleens of 8-12 weeks $d r a k 2^{-/-}$and Drak2 $2^{+/+}$littermates were cultured in medium containing LPS and IL-4 or LPS alone to induce CSR to IgG1 or IgG3, respectively. After 5 days, B cells were harvested, stained with PE-anti-B220 mAb and FITC-anti-IgG1 mAb or FITC-anti-IgG3 mAb and analyzed by FACS. The proportion of $d r a k 2^{--}$B cells switching to IgG1 and IgG3 were comparable to those of $\mathrm{Drak2}^{+/+}$B cells. 

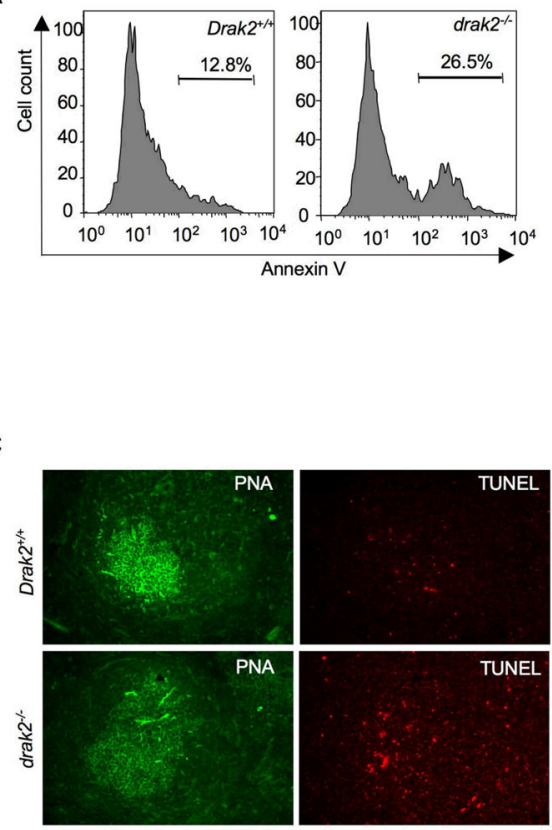

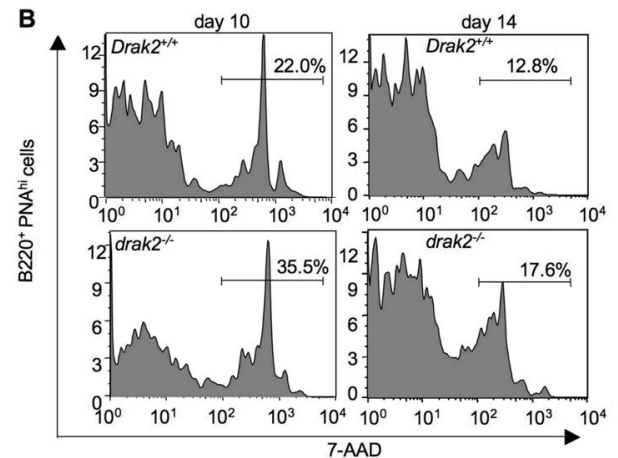

D

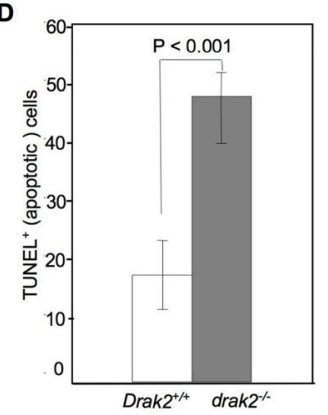

Figure 5.

Increased apoptosis in $d r a k 2^{-/-}$GC B cells. (A) Spleen B cells were harvested from 8-12 weeks $d r a k 2^{-/-}$and Drak2 $2^{+/}$littermates 14 days after immunization with $\mathrm{NP}_{16}-\mathrm{CGG}$ and stained with FITC-Annexin V and PE-anti-B220 mAb to measure apoptotic cells. drak2 ${ }^{-/-}$ mice displayed an about two-fold higher degree of B cell apoptosis than their wild-type littermates. (B) Spleen B cells were harvested from $d r a k 2^{-/-}$and Drak2 $2^{+/+}$mice 10 and 14 days after $\mathrm{NP}_{16}$-CGG immunization and stained with FITC-PNA, PE-anti-B220 mAb and 7AAD. FACS analysis showed a significantly higher proportion of apoptotic $B 220^{+} \mathrm{PNA}^{\text {hi }} \mathrm{B}$ cells from $d r a k 2^{-1-}$ mice than Drak2 $2^{+/+}$mice. (C) Spleen sections harvested from $d r a k 2^{-1-}$ and Drak2 ${ }^{+/+}$mice 7 days after $\mathrm{NP}_{16}-\mathrm{CGG}$ immunization were stained with FITC-PNA, PE-anti-B220 mAb and TUNEL (Texas red, apoptotic cell marker), and subjected to fluorescence microscopy. Red dots reflected TUNEL staining of fragmented DNA, which is characteristic of apoptosis. Counting of TUNEL red dots showed increased B cell apoptosis in $d \mathrm{rak}^{-/-}$mice GCs. Apoptotic B cells lie in an area that likely identified the light zone (original magnification: $200 \times$ ). (D) Significantly different numbers of TUNEL-positive signals (red dots) in $d r a k 2^{-/-}$and Drak2 $2^{+/+}$mice GCs. 
A

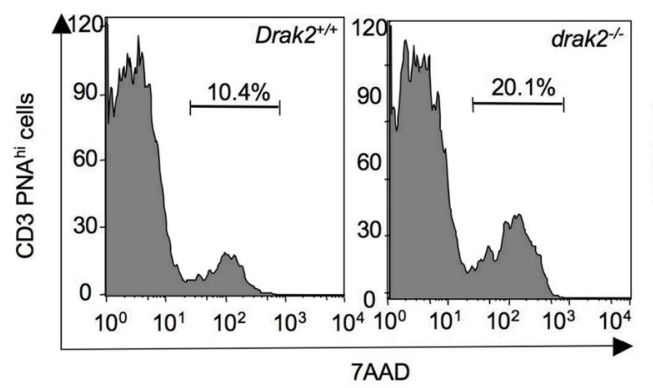

B
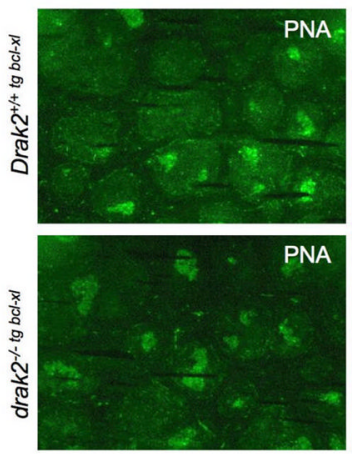

\section{C}
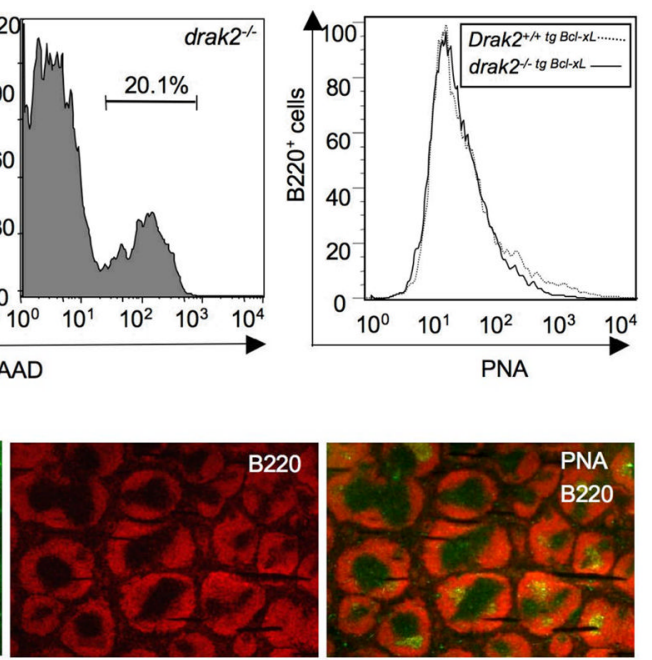

B220

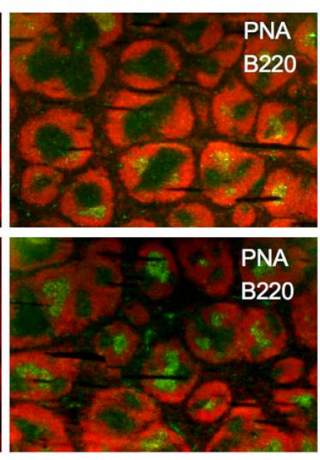

Figure 6.

Rescue of GC formation and GC B cells by the enforced expression of Bcl- $\mathrm{X}_{\mathrm{L}}$ in $\mathrm{T}$ cells in drak2 $2^{-/-}$mice. (A) T cells from spleens of 8-12 weeks drak2 $2^{-/}$and Drak2 ${ }^{+/+}$mice were harvested 14 days after immunization with $\mathrm{NP}_{16}-\mathrm{CGG}$ and stained with FITC-PNA, PEanti-CD3 mAb and 7-AAD. FACS analysis showed a higher proportion of CD ${ }^{+} \mathrm{PNA}^{\text {hi }}$ cells undergoing apoptosis in $d r a k 2^{-/-}$mice than in Drak2 $2^{+/+}$mice. (B) Spleen sections from drak2 $2^{-/} \operatorname{tg} B c l-x L$ and $D r a k 2^{+/+} \operatorname{tg} B c l-x L$ mice 14 days after $\mathrm{NP}_{16}-\mathrm{CGG}$ immunization were stained with FITC-PNA and PE-anti-B220 mAb, and subjected to Immunofluorescence microscopy. The number of GCs per field was and found to be comparable in drak2 $2^{-1-\operatorname{tg} B c l-x L}$ and Drak2 $2^{+/+\operatorname{tg} B c l-x L}$ mice (original magnification: $63 \times$ ). (C) The number of B220 ${ }^{+} \mathrm{PNA}^{\text {hi }} \mathrm{GC}$ B cells in $d r a k 2^{-1-t g} B c l-x L$ and Drak2 $2^{+/+t g B c l-x L}$ mice was also comparable, indicating a normal GC formation in $d r a k 2^{-1-\operatorname{tg} B c l-x L}$ mice. 


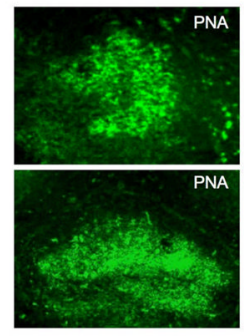

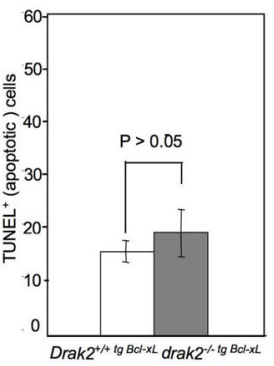

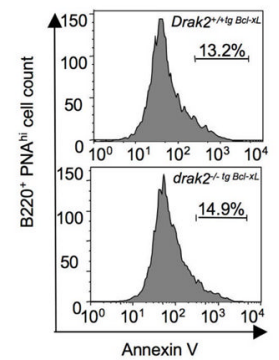

Figure 7.

Rescue of GC B cell apoptosis by enforced expression of Bcl- $\mathrm{X}_{\mathrm{L}}$ in T cells of drak2-lmice. (A) Spleen sections from $d r a k 2^{-1-\operatorname{tg} B c l-x L}$ and Drak2 $2^{+/+t g B c l-x L}$ mice were stained with FITC-PNA, PE-anti-B220 mAb and TUNEL and analyzed by fluorescence microscopy. The number of red dots, which reflects TUNEL staining of fragmented DNA in apoptotic cells, was not significantly different in $d r a k 2^{-/-\operatorname{tg} B c l-x L}$ and $D r a k 2^{+/+} \operatorname{tg} B c l-x L$ mice GCs. (B) Quantitative comparison of TUNEL ${ }^{+}$cells showing no significant difference in apoptotic cell numbers in $d r a k 2^{-/-t g B c l-x L}$ and $D r a k 2^{+/+} \operatorname{tg} B c l-x L$ mice GCs (original magnification: 200×). (C) Spleen B cells from 8-12 weeks drak2 $2^{-1-t g B c l-x L}$ and Drak2 $^{+/+} \operatorname{tg} B c l-x L$ littermates were harvested 14 day after immunization with $\mathrm{NP}_{16}-\mathrm{CGG}$ and stained with FITC-Annexin V and PE-anti-B220 mAb and analyzed by FACS. No significant difference in the number of apoptotic B cells was detected in $d r a k 2^{-1-\operatorname{tg} B c l-x L}$ and Drak2 $2^{+/+} \operatorname{tg} B c l-x L$ mice. 

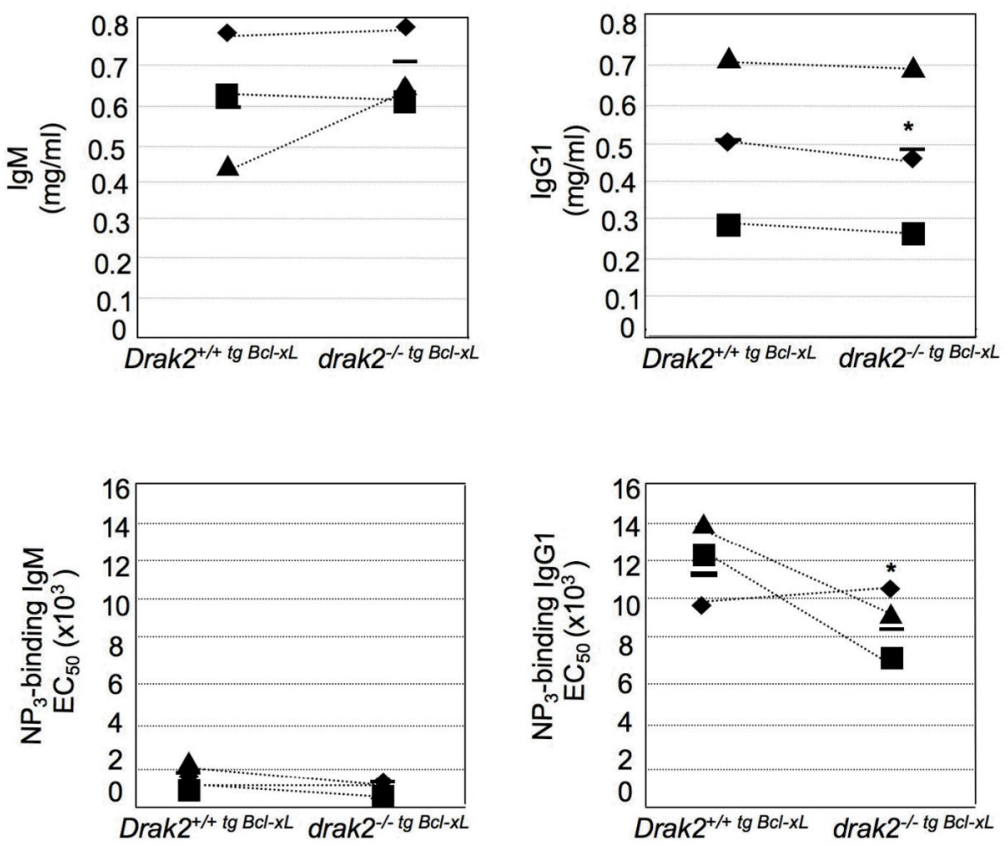

Figure 8.

Rescue of the antibody response to TD antigen by enforced Bcl-xL expression in $\mathrm{T}$ cells in

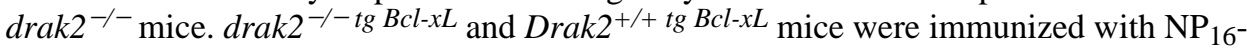
CGG at day 0 and then given booster injection on day 21. Sera from mice were collected at day 28 after the first immunization and analyzed. $\mathrm{NP}_{3}$-BSA was used to capture high affinity $\mathrm{NP}$-specific IgM and IgG1. Total IgG1 and high-affinity $\mathrm{NP}_{3}$-specific IgG1 levels in drak2 $2^{-1} \operatorname{tg} B c l-x L$ mice were comparable to their Drak2 ${ }^{+/+} \operatorname{tg} B c l-x L$ littermates. There were no significant reduction in total and $\mathrm{NP}_{3}$-specific IgG1 antibodies levels $(* p>0.05)$, likely reflecting a significant rescue of $\mathrm{B}$ cell apoptosis following enforced survival of $d r a k 2^{-1-} \mathrm{T}$ cells by Bcl-xL. 